\title{
CLINICAL FEATURES OF DYSTONIA IN ATYPICAL PARKINSONISM
}

\author{
Clecio Godeiro-Junior, Andre C. Felício, Orlando G.P. Barsottini, \\ Patricia M. de Carvalho Aguiar, Sonia M.A. Silva, Vanderci Borges, Henrique B. Ferraz
}

\begin{abstract}
Background: The association between Dystonia and Parkinson's disease (PD) has been well described especially for foot and hand dystonia. There is however few data on dystonic postures in patients with atypical parkinsonism. Objective: To evaluate the frequency and pattern of dystonia in a group of patients with atypical parkinsonism (multiple system atrophy - MSA, progressive supranuclear palsy - PSP, and corticobasal degeneration $-(B D)$ and to investigate whether dystonia could be the first presenting symptom at disease onset in those patients. Method: A total of 38 medical charts were reviewed ( $n=23 /$ MSA group; $n=7 / C B D$ group; $n=8 /$ PSP group) and data values were described as means/standard deviations. The variables evaluated were sex, age at onset, disease duration, first symptom, clinical features of dystonia and other neurological signs, response to levodopatherapy, Hoehn\&Yahr scale $>3$ after three years of disease, and magnetic resonance imaging findings. Results: The overall frequency of dystonia in our sample was $50 \%$ with $30.4 \%(n=7)$ in the MSA group, $62.5 \%(n=5)$ in the PSP group, and $100 \%(n=8)$ in the CBD group. In none of these patients, dystonia was the first complaint. Several types of dystonia were found: camptocormia, retrocollis, anterocollis, blepharoespasm, oromandibular, and foot/hand dystonia. Conclusion: In our series, dystonia was a common feature in atypical parkinsonism (overall frequency of $50 \%$ ) and it was part of the natural history although not the first symptom at disease onset. Neuroimaging abnormalities are not necessarily related to focal dystonia, and levodopa therapy did not influence the pattern of dystonia in our group of patients.
\end{abstract}

KEY WORDS: dystonia, atypical parkinsonism, multiple system atrophy, progressive supranuclear palsy, corticobasal degeneration, Parkinson's disease.

\section{Características clínicas da distonia no parkinsonismo atípico}

Resumo - Introdução: A associação de distonia e doença de Parkinson (DP) já foi bem estabelecida, principalmente para distonia focal em pé ou mão. Entretanto, há poucos dados quanto a distonia em pacientes com parkinsonismo atípico. Objetivo: Avaliar a freqüência e o padrão da distonia em um grupo de pacientes com parkisnonismo atípico (atrofia de múltiplos sistemas - AMS; paralisia supranuclear progressiva - PSP; degeneração corticobasal - DCB) e investigar se a distonia pode ser a manifestação inicial neste grupo. Método: Um total de 38 prontuários médicos foi revisado ( $n=23$ /grupo AMS; $n=8$ /grupo PSP; $n=7 /$ grupo PSP) e os dados foram apresentados em médias/desvios padrões. As variaveis avaliadas foram: sexo, idade de início, duração da doença, primeiro sintoma, características clínicas da distonia e outros sinais neurológicos, resposta ao tratamento com levodopa, escala de Hoehn \& Yahr $>3 \mathrm{em} 3$ anos de doença, e achados de ressonância magnética. Resultados: A frequência total de distonia em nosso grupo foi $50 \%$, sendo $30,4 \%$ ( $n=7)$ no grupo AMS, $62.5 \%$ ( $n=5)$ no grupo PSP e $100 \%$ (n=8) no grupo DCB. Em nenhum dos pacientes, distonia foi o primeiro sintoma. Várias apresentações de distonia foram observadas: camptocormia, anterocólis, retrocólis, distonia oromandibular, em pé e mão. Conclusão: Em nossa série, distonia foi uma caracteristica comum em pacientes com parkinsonismo atípico (frequêencia de 50\%) e fez parte da história natural em todos os grupos, embora não tenha sido o sintoma inicial em nenhum deles. Anormalidades no exame de neuroimagem não necessariamente estão relacionadas a distonia focal, e o tratamento com levodopa não influenciou o padrão da distonia em nosso grupo de pacientes.

PALAVRAS-CHAVE: distonia, parkinsonismo atípico, atrofia de múltiplos sistemas, paralisia supranuclear progressiva, degeneração corticobasal, doença de Parkinson.

Movement Disorders Unit, Department of Neurology and Neurosurgery, Federal University of São Paulo, São Paulo SP, Brazil.

Received 29 July 2008. Accepted 26 September 2008.

Dr. Clecio Godeiro-Junior - Rua Dr. Diogo de Faria 650 / 33 -04037-002 São Paulo SP - Brasil. E-mail: cleciojunior@yahoo.com.br 
Most patients who are referred to specialized movement disorders clinics with akinetic-rigid forms of parkinsonism are generally diagnosed as having Parkinson's disease (PD). The second most common group of parkinsonian patients is clinically categorized as having parkinsonism-plus disorders or atypical parkinsonism, such as multiple system atrophy (MSA) and progressive supranuclear palsy (PSP)'. Parkinsonism is considered atypical when the condition evolves rapidly, responds poorly or transiently to levodopa therapy or has other clinical and neuroimaging-associated features ${ }^{2}$. A previous series of parkinsonian patients in Brazil found a lower frequency of MSA $(1.8 \%)$ and PSP (2\%) that could reflect a short follow-up period, since it is known that many patients initially diagnosed with PD later are found to have parkinsonismplus disorders ${ }^{3}$.

Postmortem studies reveal that a substantial proportion of patients thought to have PD in life were, in fact, afflicted with other sporadic degenerative conditions such as MSA and PSP ${ }^{4}$. Dystonia, most often in the form of foot and hand posturing, occurs in untreated patients with clinical diagnosis of PD ${ }^{5}$. However, there is few data on the occurrence of the typical intermittent dystonic spasms that characterize idiopathic dystonia in MSA and PSP. Anterocollis certainly occurs in MSA, but may not be a true dystonia and more likely represents a special imbalance of rigidity in neck muscles producing a sustained posturing. Frequently, the MSA patients exhibit orofacial dystonia associated with a characteristic high-pitched dysarthria In patients with PSP, late dystonic posturing of the limbs could represent contractures, and eye-lid elevator inhibition may have been confused with blepharoespasm ${ }^{5}$. On the other hand, asymmetrical limb dystonia is a typical feature of patients with Corticobasal degeneration (CBD). Although uncommon at presentation, 60-70\% of patients with CBD develop limb dystonia during the clinical course ${ }^{6}$. Other study found a high prevalence of joint and skeletal deformities in PD, MSA, and PSPincluding "striatal" hand, foot deformities, involuntary trunk flexion, anterocollis and scoliosis ${ }^{7}$.

Our aim was to retrospectively investigate the frequency and clinical features of dystonia in a group of patients with atypical parkinsonism (MSA, PSP and CBD), and also highlights the clinical presentation of each group at first neurological visit.

\section{METHOD}

We reviewed the medical charts of twenty-three patients with probable MSA, eight patients with probable PSP and seven patients with probable CBD, according to the criteria of Gilman et al. ${ }^{8}$, Litvan et al. ${ }^{9}$, and Gibb et al. ${ }^{10}$, respectively.

We searched for the presence of dystonia and its clinical pattern in all patients. We also described demographic and clin- ical features of all groups: sex, age at onset, disease duration before first neurological visit, first symptom, clinical signs at the neurological exam, response to levodopatherapy, Hoehn\&Yahr scale $>3$ after three years of disease, and brain magnetic resonance imaging (MRI) abnormalities.

Data were described as mean \pm standard deviation, and whenever possible percentages.

This protocol was submitted to and approved by the local ethical committee.

\section{RESULTS}

On Table 1, we present the clinical features of the patients evaluated in the three groups: MSA, PSP, and CBD. On Tables 2, 3 and 4 we detailed the specific findings on dystonia in those groups aforementioned.

The frequency of dystonia in our group of patients with atypical parkinsonism was: $30.4 \%$ (7 patients) in the MSA group, 62.5\% (5 patients) in the PSP group, and 100\% (8 patients) in the CBD group. Overall, the frequency of dystonia in our series was $50 \%$. In none of these patients, dystonia was their first complaint. We did not find among the patients with dystonia and brain MRI abnormalities a topographic correlation between brain lesions and dystonia.

\section{DISCUSSION}

In this retrospective study of patients with atypical parkinsonism the overall frequency of dystonia found was high $(50 \%)$ if we compare to the frequency of patients with PD. Another interesting finding was that dystonia was not the first symptom at onset disease in any patient with atypical parkinsonism.

A common form of dystonia in patients with MSA is a severe, isolated anterocollis ${ }^{5,11}$. In our group of patients with MSA, only three subjects presented cervical dystonia ( 2 anterocollis and 1 retrocollis). Cervical dystonia, contralateral arm, hand and foot dystonias, occurring alone or in various combinations, may be the manifestation of a structural lesion involving the head of the caudate nucle$u^{12}$. In only one of our patients (patient 7 in MSA group) we were able to find an MRI abnormality that could justify dystonia. In fact, MRI is a useful diagnostic tool in the early course of MSA and it can be used to differentiate parkinsonian disorders ${ }^{13,14}$, but there is no clinical radiological correlation to dystonia phenomenom.

Since PSP was first characterized in $1964^{15}$, dystonic manifestations have been reported only sporadically. Retrocollis or "axial dystonia in extension" is the only such manifestation, which has been disclosed; however, the pathogenesis of this tonic, rigid extended posture is probably distinct from other forms of dystonia and is more correlated with interstitial nucleus of Cajal lesions than lesions of the basal ganglia ${ }^{16}$. The neck positioning 
Table 1. Clinical profile of patients with atypical parkinsonism and dystonia.

\begin{tabular}{|c|c|c|c|}
\hline & $\begin{array}{l}\text { Multiple system } \\
\text { atrophy (MSA) } \\
\qquad N=23\end{array}$ & $\begin{array}{l}\text { Progressive supranuclear } \\
\text { palsy (PSP) } \\
\mathrm{N}=8\end{array}$ & $\begin{array}{c}\text { Corticobasal } \\
\text { degeneration (CBD) } \\
\mathrm{N}=7\end{array}$ \\
\hline Male/Female & $13 / 10$ & $3 / 5$ & $3 / 4$ \\
\hline Onset age (year-old) & $57.1 \pm 9.3$ & $64.7 \pm 10.3$ & $62.7 \pm 6.8$ \\
\hline Disease duration before diagnosis (months) & $30.4 \pm 12.6$ & $36.3 \pm 26.2$ & $52.3 \pm 26.1$ \\
\hline Dystonia & $7(30.4 \%)$ & $5 / 8(62.5 \%)$ & $7(100 \%)$ \\
\hline \multicolumn{4}{|l|}{ First symptom } \\
\hline Gait disorder & 11 & 2 & 1 \\
\hline Falls & 4 & 5 & 0 \\
\hline Rigidity & 1 & 0 & 4 \\
\hline Bradikynesia & 6 & 0 & 2 \\
\hline Tremor & 1 & 1 & 0 \\
\hline Dystonia & 0 & 0 & 0 \\
\hline Asymmetric parkinsonism & $2(8.6 \%)$ & $3(37.5 \%)$ & $7(100 \%)$ \\
\hline$H \& Y \geq 3$ in 3 years & $20(86.9 \%)$ & $8(100 \%)$ & $6(85.7 \%)$ \\
\hline Response to levodopa & $4(17.3 \%)$ & 0 & $1(14.3 \%)$ \\
\hline Bradikinesia & $23(100 \%)$ & $8(100 \%)$ & 6 \\
\hline Rigidity & $22(95.6 \%)$ & $8(100 \%)$ & $7(100 \%)$ \\
\hline Tremor & $4(17.3 \%)$ & $2(25 \%)$ & $1(14.3 \%)$ \\
\hline Postural unsteadiness & $22(95.6 \%)$ & $7(87.5 \%)$ & $2(28.5 \%)$ \\
\hline Ocular movement abnormalities & $8(34.7 \%)$ & $8(100 \%)$ & $3(42.8 \%)$ \\
\hline Postural hypotension & $20(86.9 \%)$ & $1(12.5 \%)$ & $1(14.3 \%)$ \\
\hline Sphincters disorders & $15(65.2 \%)$ & $1(12.5 \%)$ & 0 \\
\hline Erectile dysfunction & $11(47.8 \%)$ & 0 & 0 \\
\hline Cold blue hands & $6(26 \%)$ & 0 & $1(14.3 \%)$ \\
\hline Pyramidal signs & $12(52.1 \%)$ & $3(37.5 \%)$ & $4(57.1 \%)$ \\
\hline Cerebellar signs & $5(21.7 \%)$ & 0 & 0 \\
\hline DSM-IV dementia & $3(13 \%)$ & 0 & $1(14.3 \%)$ \\
\hline Dysphagia & $14(60.8 \%)$ & $7(85.5 \%)$ & $3(42.8 \%)$ \\
\hline Dysartria & $16(69.5 \%)$ & 8 (100\%) & $3(42.8 \%)$ \\
\hline Alien hand & 0 & 0 & 4 (57.1\%) \\
\hline
\end{tabular}

Table 2. Patients with MSA and dystonia.

\begin{tabular}{|c|c|c|c|c|c|c|c|}
\hline & Sex & $\begin{array}{c}\text { Onset age } \\
\text { (years) }\end{array}$ & $\begin{array}{l}\text { Disease duration } \\
\text { (months) }\end{array}$ & $\begin{array}{c}\text { First } \\
\text { symptom }\end{array}$ & $\begin{array}{l}\text { Pattern of } \\
\text { dystonia }\end{array}$ & $\begin{array}{l}\text { Levodopa } \\
\text { response }\end{array}$ & Brain MRI \\
\hline 1 & $\mathrm{~F}$ & 54 & 36 & Falls & Anterocollis & No & Pons and cerebellum atrophy \\
\hline 2 & $\mathrm{~F}$ & 64 & 12 & Gait disorder & Camptocormia & No & Normal \\
\hline 3 & $\mathrm{~F}$ & 62 & 36 & Rigidity & Left foot & No & Normal \\
\hline 4 & $M$ & 50 & 24 & Bradikinesia & Left foot & No & Normal \\
\hline 5 & $\mathrm{~F}$ & 76 & 36 & Falls & Anterocollis & No & Normal \\
\hline 6 & $M$ & 64 & 36 & Gait disorder & Retrocollis & Yes & Mesencephalum atrophy \\
\hline 7 & M & 43 & 24 & Gait disorder & Left arm & No & $\begin{array}{c}\text { Putamen atrophy and } \\
\text { putaminal rim }\end{array}$ \\
\hline
\end{tabular}


Table 3. Patients with PSP and dystonia.

\begin{tabular}{cccccccc}
\hline & Sex & $\begin{array}{c}\text { Onset age } \\
\text { (years) }\end{array}$ & $\begin{array}{c}\text { Disease duration } \\
\text { (months) }\end{array}$ & $\begin{array}{c}\text { First } \\
\text { symptom }\end{array}$ & $\begin{array}{c}\text { Pattern of } \\
\text { dystonia }\end{array}$ & $\begin{array}{c}\text { Levodopa } \\
\text { response }\end{array}$ & Brain MRI \\
\hline 1 & F & 74 & 72 & Falls & Oromandibular & No & Mild Microangipathy \\
2 & F & 64 & 30 & Falls & Right arm & No & Nummingbird" sign \\
3 & M & 69 & 48 & Falls & Retrocollis & Generalized cerebral atrophy \\
4 & F & 60 & 36 & Falls & Left arm & No & "Hummingbird" sign \\
5 & F & 42 & 9 & Gait disorder & Retrocollis & No & "Hummingbird" and \\
& & & & & & &
\end{tabular}

Table 4. Patients with CBD and dystonia.

\begin{tabular}{|c|c|c|c|c|c|c|c|c|}
\hline & Sex & $\begin{array}{l}\text { Onset age } \\
\text { (years) }\end{array}$ & $\begin{array}{l}\text { Disease duration } \\
\text { (months) }\end{array}$ & $\begin{array}{c}\text { First } \\
\text { symptom }\end{array}$ & $\begin{array}{l}\text { Pattern of } \\
\text { dystonia }\end{array}$ & $\begin{array}{l}\text { Myoclonic } \\
\text { jerks }\end{array}$ & $\begin{array}{l}\text { Levodopa } \\
\text { response }\end{array}$ & Brain MRI \\
\hline 1 & $\mathrm{~F}$ & 65 & 60 & Gait disorder & Left arm & Yes & No & $\begin{array}{l}\text { Right frontal } \\
\text { lobe atrophy }\end{array}$ \\
\hline 2 & $M$ & 50 & 84 & Rigidity & Right arm & Yes & No & Normal \\
\hline 3 & $\mathrm{~F}$ & 60 & 24 & Rigidity & Left arm & No & No & $\begin{array}{l}\text { Right parietal and } \\
\text { tempotal lobes atrophy }\end{array}$ \\
\hline 4 & $\mathrm{~F}$ & 62 & 72 & Bradikinesia & Right arm & Yes & No & Normal \\
\hline 5 & $F$ & 71 & 72 & Bradikinesia & $\begin{array}{l}\text { Right arm and } \\
\text { retrocollis }\end{array}$ & Yes & No & $\begin{array}{l}\text { Left frontal lobe } \\
\text { atrophy }\end{array}$ \\
\hline 6 & M & 62 & 36 & Rigidity & $\begin{array}{l}\text { Left arm and } \\
\text { blepharoespasm }\end{array}$ & No & No & $\begin{array}{l}\text { Global cortical } \\
\text { atrophy (right > left) }\end{array}$ \\
\hline 7 & $M$ & 69 & 18 & Rigidity & Left arm & Yes & No & Normal \\
\hline
\end{tabular}

in PSP tends to be fixed and does not alter with posture or activity as idiopathic dystonia does. Patients fail to show sensory tricks for improving the posturing, diurnal variation is absent ("morning benefit"), and painful neck spasms and hypertrophic muscles are not seen ${ }^{17}$. Two of our patients (patients 3 and 5) presented retrocollis and MRI abnormalities in brainstem. The MRI findings in patients with atypical parkinsonism reflect the involvement of many structures. The midbrain atrophy is particularly well demonstrated on midline sagittal images ("Hummingbird sign"), showing reduced midbrain diameter, enlarged cerebral aqueduct and thinned quadrigeminal plate. Signal abnormalities are mild and consist of hyperintensity in the periaqueductal region on $\mathrm{T}_{2}$-weighted sequences ("Morning Glory sign") 18,19. The most widely reported dystonic manifestation on PSP is blepharospasm ${ }^{20}$, but none of our patients presented such manifestation. Two of our patients (patients 2 and 4) presented limb dystonia. It is possible that limb dystonia in PSP is an indicator of concomitant cortical and basal ganglia neuropathological changes. It is becoming increasingly recognized that such cortical pathology does occur in $\mathrm{PSP}^{17}$. Interestingly, oromandibular dystonia was observed in one of our patients and it was not related to levodopa therapy. The potential role of medication, especially levodopa, must be considered when dealing with dystonia in patients with PSP $^{17}$. A Brazilian series of PSP patients observed that $13 \%$ had transiently good response to levodopa, but it did not point out whether these patients also presented dystonia ${ }^{21}$. None of our patients with PSP responded to levodopa, including those who presented dystonia.

Classically, typical features of CBD can be categorized into movement disorders (akinesia, rigidity, postural instability, limb dystonia, cortical myoclonus and postural/intention tremor) and cortical signs such as cortical sensory loss, apraxia and Alien hand phenomenon ${ }^{22}$. A rigid, dystonic posture arm with some fingers extended and others forcibly flexed into the palm causing skin maceration characteristically develops early in the course of the illness in a substantial minority of patients ${ }^{5,22}$. Jerking of the affected limb due to action-induced and stimulus sensitive focal reflex myoclonus commonly precedes or accompanies the development of such dystonic postures and, if rhythmic, may mimic tremor ${ }^{23}$. In our series, all patients with CBD presented limb dystonia, and five of them also had associated myoclonus. The brain MRI was abnormal in four patients, all presenting asymmetrical brain atrophy (Table 4). In these patients the side with 
more prominent atrophy was opposite to the side of limb dystonia. MRI findings of atrophy in the perirolandic gyri, atrophy of the basal ganglia, and $\mathrm{T}_{2}$ prolongation in the posterolateral putamen are useful evidence supporting the clinical diagnosis of corticobasal degeneration ${ }^{24}$. As expected, dystonia was not the chief complaint in any patient and did not respond to levodopa therapy.

Clinico-pathologic studies are needed to disclose the relationship between these dystonic manifestations and the pathological substrates of these atypical parkinsonisms. We did not have a longer follow-up that could allow the observation of dystonia progression, and of those patients who initially did not have dystonic features but later developed these signs correlating to levodopa therapy.

In conclusion, in our series dystonia was a common feature in atypical parkinsonism (overall frequency 50\%) and it was part of the natural history although not the first symptom at disease onset. Moreover, neuroimaging abnormalities are not necessarily related to focal dystonia, and levodopa therapy did not influence the pattern of dystonia in our group of patients. Prospective studies of natural history and post-mortem brain pathological analysis are necessary to disclosure a better comprehension of dystonia phenomenology in atypical parkinsonism.

\section{REFERENCES}

1. Jankovic J, Rajput A, McDermott MP, Perl DP. The evolution of diagnosis in early Parkinson disease. Arch Neurol 2000;57:369-372.

2. Brooks DJ. Diagnosis and management of atypical parkinsonian syndromes. J Neurol Neurosurg Psychiatry 2002;72(Suppl 1):110-116.

3. Cardoso F, Camargos ST, Silva GA Jr. Etiology of parkinsonism in a Brazilian Movement Disorders Clinic. Arq Neuropsiquiatr 1998;56:171-175.

4. Albanese A, Colosimo C, Bentivoglio AR, et al. Multiple system atrophy presenting as parkinsonism: clinical features and diagnostic criteria. J Neurol Neurosurg Psychiatry 1995;59:144-151.

5. Rivest J, Quinn N, Marsden CD. Dystonia in Parkinson's disease, multiple system atrophy, and progressive supranuclear palsy. Neurology 1990;40:1571-1578.
6. Rinne JO, Lee MS, Thompson PD, et al. Corticobasal degeneration: a clinical study of 36 cases. Brain 1994;117:1183-1196.

7. Ashour R, Jankovic J. Joint and skeletal deformities in Parkinson's disease, multiple system atrophy, and progressive supranuclear palsy. Mov Disord 2006;21:1856-1863.

8. Gilman S, Low PA, Quinn N, et al. Consensus statement on the diagnosis of multiple system atrophy. J Neurol Sci 1999;163:94-98.

9. Litvan I, Agyd Y, Calne D, et al. Clinical Research criteria for the diagnosis of progressive supranuclear palsy (Steele-Richardson-Olszewski syndrome): report of the NINDS-SPSP International Workshop. Neurology 1996;47:1-9.

10. Gibb WRG, Luthert PJ, Marsden CD. Corticobasal degeneration. Brain 1989;112:1171-1192.

11. Quinn N. Disproportionate anterocollis in multiple system atrophy. Lancet 1989;1:844.

12. Obeso JA, Gimenez-Roldan S. Clinicopathological correlation in symptomatic dystonia. Adv Neurol 1988;50:113-122.

13. Seppi K, Schocke MF Wenning GK, Poewe W. How to diagnose MSA early: the role of magnetic resonance imaging. J Neural Transm 2005;112:1613-1624.

14. Albuquerque AV, Freitas MRG, Cincinatus D, Harouche MBB. Multiple system atrophy: clinical-radiological correlation. Arq Neuropsiquiatr 2007;65:512-515.

15. Steele JC, Richardson JC, Olszewski J. Progressive supranuclear palsy. Arch Neurol 1964;10:333-359.

16. Fukushima-Kudo J, Fukushima K, Tashiro K. Rigidity and dorsiflexion of the neck in progressive supranuclear palsy and the interstitial nucleus of Cajal. J Neurol Neurosurg Psychiatry 1987;50:1197-203.

17. Barclay CL, Lang AE. Dystonia in progressive supranuclear palsy. J Neurol Neurosurg Psychiatry. 1997;62:352-356.

18. Barsottini OG, Ferraz HB, Maia AC Jr, Silva CJ, Rocha AJ. Differentiation of Parkinson's disease and progressive supranuclear palsy with magnetic resonance imaging: the first Brazilian experience. Parkinsonism Relat Disord. 2007;13:389-393.

19. Schrag A, Good CD, Miszkiel K, et al. Differentiation of atypical parkinsonian syndromes with routine MRI. Neurology 2000;54:697-702.

20. Pfaffenbach DD, Layton DD, Kearns TP. Ocular manifestations manifestations in progressive supranuclear palsy. Am J Ophthalmol 1972;74:1179-1184.

21. Carrilho PEM, Barbosa ER. Progressive supranuclear palsy in a sample of Brazilian population: clinical features of 16 patients. Arq Neuropsiquiatr 2002;60:917-922.

22. Riley DE, Lang AE, Lewis A, et al. Cortical-basal ganglionic degeneration. Neurology 1990;40:1203-1212.

23. Thompson PD, Shibasaki H. Myoclonus in corticobasal degeneration and other neurodegenerations. Adv Neurol 2000;82:69-82.

24. Tokumaru AM, O'uchi T, Kuru Y, Maki T, Murayama S, Horichi Y. Corticobasal degeneration:MR with histopathologic comparison. AJNR Am J Neuroradiol. 1996;17:1849-1852. 